\title{
Introduction
}

\author{
Elizabeth Bryan and Ronald Higgins
}

It is widely recognised that the numbers of twins, triplets (and more) are fast increasing wherever assisted reproductive technology (ART) is practised. It is less widely realised that so, therefore, are the numbers of multiples who die at birth or in their early months or who survive with lifelong disabilities. Both death and disability produce parental bereavement as indeed do miscarriage and multifetal pregnancy reduction.

Other twins will have a uniquely close relationship through a sometimes long life only for one of them to be devastated by the loss of the other.

These kinds of bereavement, with their many special features and complications, have received far too little attention. We decided therefore that we should at least publish the proceedings of the Symposium The Loss of a Twin: Theory and Practice Revisited which was held at the International Congress on Twin Studies in London in July 2001. It then became clear to us that the subject merited a special issue of Twin Research which could include not only other relevant research papers and review articles but, as importantly, the personal experiences of those who had suffered such bereavement. With book and video reviews and a list of relevant organisations (now to be regularly updated on the ISTS website), we hope we have added further to a valuable resource.

We shall welcome correspondence and further reports of work with bereaved twins and their families.

\section{The Scale of the Problem}

From conception through pregnancy and early childhood the mortality rate in twins and higher multiples is relatively high (Macfarlane \& Mogford, 2000). However over 20\% of multiple pregnancies will not be recognised as such if one fetus dies and is reabsorbed during the first trimester - the 'vanishing twin syndrome' (Landy et al., 1986; Pharoah et al., 2001).

\section{Spontaneous Abortion}

Figures on the incidence of spontaneous abortion in multiple pregnancies should be interpreted with caution as twins are often not recognised in early losses but most studies have found an increased incidence in multiple pregnancies (Baldwin, 1993; Livingstone \& Poland, 1980; Uchida et al., 1983) and that the incidence rises with the number of fetuses particularly in the second trimester (Baldwin, 1993).

There is a high proportion of monochorionic conceptions amongst aborted embryos and fetuses and this suggests that there may be some basic abnormalities of the

monozygotic (MZ) twinning process that contribute to embryonic and fetal death such as asymmetric twinning including haemodynamic imbalance in the shared circulation (Baldwin, 1993; Hrubic \& Robinette, 1984)

\section{Intrauterine Death}

Despite improvements in obstetric care the risks to a twin fetus remain higher than a singleton throughout the pregnancy. A second trimester intrauterine death will result in a fetus papyraceus. This probably occurs in about one in 150-200 twin pregnancies (Baker \& Doeing, 1982; Saier et al., 1975) and is reportedly higher in triplet pregnancies (Blickstein et al., 1987).

The twin stillbirth rate is about three times that of a singleton. There are a number of factors unique to a multiple pregnancy that contribute to this higher rate. There is again the haemodynamic imbalance that often occurs in monochorionic twins (two thirds of MZ pairs) resulting in the twin twin transfusion syndrome. Cord complications in monoamniotic twins can cause occlusion of the blood flow to one or both fetuses. In a multiple pregnancy there is a higher incidence of lethal malformations, such as acardia and conjoined twinning.

Finally there are the conflicting needs of the two fetuses that can arise for various reasons. For example, in twins with discordant intrauterine growth, or severe rhesus isoimmunisation, the life of one twin may have to be sacrificed, or at least risked, for the sake of the healthy survival of the other. The risk, by delaying delivery, of an intrauterine death of one has to be weighed against the risk of losing both newborn infants from the complications of prematurity, if the babies are delivered too early.

Fetal death in one of $M Z$ twins has serious implications for the survival of the co-twin who then has an almost twenty fold risk of death in utero as well as twice the chance of dying in the neonatal period (West et al., 1999).

\section{Perinatal Mortality}

Perinatal mortality data in multiple births can sometimes be misleading. If a multiple birth occurs before 24 weeks gestation and includes both live births and dead fetuses, the fetal deaths are not registrable. Thus some very preterm infants from multiple conceptions will be registered as singletons (or lower order multiples). The reverse may also occur. If fetuses are born dead, together with live births, in a multiple birth after 24 weeks, they should be registered as stillborn even if they had actually died many weeks earlier.

Although there has been a somewhat greater fall in perinatal mortality rates in twins than singletons in recent years (Parker et al., 2001) - and even more in triplets (Macfarlane \& Mugford, 2000) - a striking difference 
remains. The perinatal mortality rate (stillbirth and deaths in the first week of life) is over four times higher in twins and five-nine times higher in triplets (Macfarlane \& Mugford, 2000). Amongst quadruplets the average rate is very much higher still but varies greatly.

The main contributor to the high perinatal death toll in multiples is prematurity and its complications. Twins, and even more so, higher order births are therefore particularly vulnerable in the neonatal period and, unlike singletons, have a higher neonatal mortality than still birth rate.

When adjusted for birthweight however, twins do better than singletons in the low birthweight groups between $1000 \mathrm{~g}$ and 2500g (Dunn \& Macfarlane, 1996; Parker et al., 2001; West et al., 1999). This is presumably due to the relatively greater gestational age of twins, and therefore maturity, compared to singleborn infants at any given weight. Only above $2500 \mathrm{~g}$ does the rate become higher in twins. As with singletons male twins have a higher mortality rate at all stages of pregnancy and early childhood.

Many studies have shown higher perinatal mortality rates amongst like-sex and $M Z$ twins but only recently has it been shown that this higher rate (in both stillbirth and neonatal deaths) was limited to monochorionic $M Z$ twins and that there was no significant difference between DZ and dichorionic MZ pairs (Loos et al., 1998).

Although a set of octuplets has been born alive, the numbers of very high multiple sets are so small that mortality rates above quads are not available. Many of the very high multiple pregnancies will inevitably end in a second trimester miscarriage and are therefore not included in the national multiple birth statistics.

Several countries show a higher perinatal mortality rate amongst offspring of iatrogenic pregnancies even when allowance is made for the higher proportion of multiple births, with their associated prematurity (HFEA, 2000; Hurst \& Lancaster, 2001). The explanation is uncertain but the cause of the parental subfertility may be a contributory factor.

\section{Sudden Infant Death Syndrome (SIDS)}

The incidence of SIDS in twins appears to be about double that of infants in general (Beal, 1983; Malloy, 1999) but this difference is entirely attributable to their lower birthweight. In Molloy's large study the relative risk of the second twin dying from SIDS was 8.17 but in only one case did both twins die on the same day. Earlier reviews showed a higher risk of recurrent SIDS in twins but the criteria they employed for SIDS may have been less strict.

Simultaneous SIDS, defined as the death of a twin pair within 24 hours, appears to be rare. Koehler (2001) reviewed the 41 cases reported from 1900 to 1998. Many of them failed to fulfil current criteria for SIDS and there was no evidence of increased concordancy amongst MZ twins.

\section{Death in Later Childhood}

Twins are little if any more likely to die in later childhood than singletons. Baird and colleagues (1998) found that although the mortality rate declined progressively it remained significantly higher than that of the general population until the age of five years. This increase is not surprising as some of those who suffered from severe neonatal problems or congenital anomalies may die of long term complications well beyond infancy.

\section{Special Needs in Twins}

The disabilities experienced by multiple birth children are mostly of course the same as those suffered by singleborn children. However, the origin of some impairments may be unique to twins or occur with a different frequency.

\section{Congenital Anomalies}

It is generally accepted that congenital malformations are more common in twins than singletons but the higher rate is only found in MZ twins (Little \& Bryan, 1988). With the exception of neural tube defects, $M Z$ twins are more likely to be concordant for all malformations than DZ twins. Nevertheless, for most malformations, all twins, including $\mathrm{MZ}$ pairs are still more often than not discordant.

Malformations in twins can be divided into three groups. The largest are those that have the same incidence in twins as in singletons. Then there are those that are unique to $\mathrm{MZ}$ twins which include conjoined twins. (Even when separated, these may suffer not only from the result of the shared organs but from additional malformations such as cardiac and neural tube defects.) Finally there are malformations that are not unique in multiple conceptions but are more common such as cardiac defects which are significantly increased in MZ twins (Burn \& Corney, 1984).

\section{Cerebral Palsy}

With the well recognised intrauterine and neonatal hazards they experience, it is not surprising to find that multiple birth children have a much higher incidence of cerebral palsy than singleborn children. However, it is only relatively recently that this has been confirmed in population studies (Grether et al., 1993; Petterson et al., 1993; Yokayam et al., 1995; Williams et al., 1996).

The relative risk for singletons, twins and triplets in the Western Australian study was 1:6.5:38 (Petterson et al., 1993). However the risk per pregnancy (and therefore of a family having a child with a disability) was $1: 8: 47$. Following the intrauterine death of a co-twin or triplet there is a still greater risk of cerebral palsy for the surviving baby $-10 \%$ for twins, and 29\% for triplets (Stanley $\&$ Petterson, 1995). This is a well-recognised outcome following a second trimester intrauterine death but the effect of a first trimester fetal death is yet to be established (Pharoah \& Cooke, 1996).

All couples considering any form of treatment that may induce a multiple pregnancy have a need and right to be made aware of these statistics as well as those of perinatal mortality.

\section{$\overline{\text { References }}$}

Baird, J., Osmond, C., Bowes, I., \& Phillips, D. I. W. (1998). Mortality from birth to adult life: A longitudinal study of twins. Early Human Development, 53, 73-79.

Baker, V. V., \& Doering, M. C. (1982). Fetus papyraceus, an unreported congenital anomaly of the surviving infant. American Journal of Obstetrics and Gynecology, 143(2), 234-235. 
Baldwin, V. J. (1993). The mortality of twins. In V. J. Baldwin, Pathology of multiple pregnancy (Chpt. 5; pp. 87-132). New York: Springer Verlag.

Blickstein, I., Shoham-Schwartz, Z., Lancet, M., \& Borenstein, R. (1987). Characterization of the growth-discordant twins. Obstetrics and Gynecology, 70, 11-15.

Burn, J., \& Corney, G. (1984). Congenital heart defects and twinning. Acta Geneticae Medicae Gemellogiae, 33, 61-69.

Campbell, D. M., \& MacGillivray, I. (1988). Outcome of twin pregnancies. In I. MacGillivray, D. M. Campbell, B. Thompson (Eds.), Twinning and twins (Chpt. 10; pp. 179-205). Chichester: John Wiley.

Dunn, M., \& Macfarlane, A. (1996). Recent trends in the incidence of multiple births and associated mortality in England and Wales. Archives of Disease in Childhood, 75, F10-19.

Grether, J. K., \& Nelson, K. B., \& Cummins, C. K. (1993). Twinning and cerebral palsy: Experience in four Northern Californian counties, births 1983 through 1985. Pediatrics, 92, 854-858.

Hrubec, Z., \& Robinette, C. D. (1984). The study of human twins in medical research. New England Journal of Medicine, 310, 435-441.

Hurst, T., \& Lancaster, P. (2001). Assisted conception in Australia and New Zealand 1999 and 2000 (Assisted Conception Series no 6). Sydney: AIHW.

Landy, H. J., Weiner, S., Corson, S. L., Batzer, F. R., \& Bolognese, R. J. (1986). The 'vanishing twin': Ultrasonic assessment of fetal disappearance in the first trimester. American Journal of Obstetrics and Gynecology, 155, 14-19.

Little, J., \& Bryan, E. M. (1988). Congenital anomalies. In I. MacGillivray, D. M. Campbell, \& B. Thompson (Eds.), Twinning and twins (Chpt. 11; pp. 207-240). Chichester: John Wiley.

Livingston, J. E., \& Poland, B. J. (1980). A study of spontaneously aborted twins. Teratology, 21, 139-148.

Loos, R., Derom, C., Vlietinck, R., \& Derom, R. (1998). The East Flanders Prospective Twin Survey (Belgium): A population-based register. Twin Research, 1, 167-175
Macfarlane, A., \& Mogford, M. (2000). Characteristics of babies. In A. Macfarlane, \& M. Mogford (Eds.), Birth counts (Chpt. 6; pp. 165-189). London: The Stationery Office.

Parker, J. D., Schoendorf, K. C., \& Kiely, J. L. (2001). A comparison of recent trends in infant mortality among twins and singletons. Paediatrics and Perinatal Epidemiology, 15, 12-18.

Petterson, B., Nelson, K. B., Watson, L., \& Stanley, F. (1993). Twins, triplets and cerebral palsy in births in Western Australia in the 1980s. British Medical Journal, 307, 1239-1243.

Pharoah, P. O. D., Anand, D., Platt, M. J., \& Briscoe, L. (2001). Epidemiology of the vanishing twin. Twin Research, 4, 202.

Pharoah, P. O. D., \& Cooke, R. T. (1996). Cerebral palsy and multiple births. Archives of Disease in Childhood, 75, F175-178.

Saier, F., Burden, L., \& Cavanagh, D. (1975). Fetus papyraceus; An unusual case with congenital anomaly of the surviving fetus. Obstetrics and Gynecology, 45, 217-220.

Stanley, F., \& Petterson, B. (1995). Cerebral palsy in multiple births: The changing epidemiological patterns. In R. H. Ward, \& M. Whittle (Eds.), Multiple pregnancy (Chpt. 31; pp. 309-325). London: RCOG.

The Human Fertilisation and Embryology Authority. (2000). The Human Fertilisation and Embryology Authority Annual Report. London, HFEA

Uchida, I. A., Freeman, V. C. P., Gedeon, M., \& Goldmaker, J. (1983). Twinning rate in spontaneous abortions. Journal of Human Genetics, 35, 987-993.

West, C. R., Adi, Y., \& Pharoah, P. O. D. (1999). Fetal and infant death in mono- and di-zygotic twins in England and Wales 1982-91. Archives of Disease in Childhood, 80, F217-220.

Williams, K., Henessy, E., \& Alberman, E. (1996). Cerebral palsy: Effects of twinning, birthweight and gestational age. Archives of Disease in Childhood, 7, F178-182.

Yokoyama, Y., Shimizu, T., \& Hayakawa, K. (1995). Prevalence of cerebral palsy in twins, triplets and quadruplets. International Journal of Epidemiology, 24, 943-948. 